\title{
Psychotic Mania and Nonpsychotic Mania: A Comparative, Cross-sectional Study
}

\author{
Swarna Hemamalini Mohan Sundaram ${ }^{1}$, Ganesh Kini Kota² ${ }^{2}$ Rohan D Mendonsa ${ }^{3}$, Ravichandra Karkal ${ }^{4}$, Anil Kakunje ${ }^{5}$, \\ Varikara Veetil Mohan Chandran ${ }^{6}$
}

\begin{abstract}
Aims and objectives: Though mania is considered a mood disorder and presents with elevated/irritable mood, increased goal-directed activity, pressure of speech, and flight of ideas, they can also manifest with psychotic symptoms including Schneiderian first-rank symptoms. The present study was undertaken to compare and study any differences between psychotic mania and nonpsychotic mania groups.

Materials and methods:We compared the sociodemographic and clinical variables between 30 psychotic and 30 nonpsychotic mania patients, i.e., a total of 60 patients. After obtaining ethical clearance from the Institutional Ethics Committee, we used the Mini International Neuropsychiatric Interview to conduct structured diagnostic interview and the Young's Mania Rating Scale (YMRS) to assess the severity of mania.

Results: Young's Mania Rating Scale scores (Mann-Whitney $U=785.5 ; p<0.05$ ) and duration of hospital stay (Mann-Whitney $U=587.0 ; p=0.04$ ) were significantly different between the two groups. During correlation analysis, negative correlation between age of onset and number of episodes of psychotic mania ( $p=-0.477 ; p=0.008$ ) was seen. A moderate association between duration of hospitalization and YMRS scores $(p=0.331 ; p=0.010)$ was also observed.

Conclusion: Psychotic mania tends to be more severe and needs longer duration of stay in hospital compared to nonpsychotic mania. The negative correlation between age of onset and the number of episodes of psychotic mania highlights the need for specialized early interventions to treat such cases to alter the course of the disorder and improve the socio-occupational impairment.

Keywords: Age of onset, Bipolar disorder, Nonpsychotic mania, Psychotic mania.

Indian Journal of Private Psychiatry (2021): 10.5005/jp-journals-10067-0084
\end{abstract}

\section{INTRODUCTION}

Bipolar affective disorder is a severe psychiatric disorder that is associated with high levels of long-term morbidity, comorbidity, hospitalization, and disability. ${ }^{1}$ The higher morbidity and mortality results from suicide, accidents, and adverse outcomes due to the use of comorbid substance and medical illnesses. ${ }^{2}$ Bipolar disorder primarily because of its early onset and chronic nature across the life span has been identified as the sixth leading cause of disabilityadjusted life years in the world among people aged 15-44 years. ${ }^{3}$

During manic episodes in addition to elevated/irritable mood, increased goal-directed activity, pressure of speech, and flight of ideas, psychotic symptoms have also been recorded. In a survey of 26 studies of psychotic symptoms in mania, Goodwin and Jamison ${ }^{4}$ concluded that approximately $58 \%$ of patients had history of at least one psychotic symptom. Psychotic symptoms are frequently reported by subjects suffering from bipolar disorder, being experienced by at least $68 \%$ of them. ${ }^{5}$ Of note, up to $50 \%$ of patients with a manic episode can manifest psychotic symptoms. ${ }^{6}$ Schneiderian first-rank symptoms have also been reported in $8-23 \%$ of manic cases. ${ }^{7}$ Furthermore, psychotic bipolar patients were found to have more working impairment and social dysfunction than nonpsychotic ones. ${ }^{8}$ Hence, it is important to study the differences between psychotic and nonpsychotic manias because if there are significant differences between the two entities then a distinct approach to management maybe needed.

In the light of abovementioned considerations, the present study was undertaken with the following objectives: (a) to describe the sociodemographic and clinical characteristics of psychotic mania and nonpsychotic mania and (b) to compare the differences in the
${ }^{1}$ SMS Hospital, Kozhikode, Kerala, India

2,4,5 Department of Psychiatry, Yenepoya Medical College, Mangaluru, Karnataka, India

${ }^{3}$ Department of Psychiatry, NorthWestern Mental Health, Melbourne, Victoria, Australia

${ }^{6}$ Emeritus Professor, Department of Psychiatry, Yenepoya Medical College, Mangaluru, Karnataka, India

Corresponding Author: Ganesh Kini Kota, Department of Psychiatry, Yenepoya Medical College, Mangaluru, Karnataka, India, Phone: +91 7899005818, e-mail: ganeshkinik@yenepoya.edu.in

How to cite this article: Sundaram SHM, Kota GK, Mendonsa RD, et al. Psychotic Mania and Nonpsychotic Mania: A Comparative, Cross-sectional Study. Ind J Priv Psychiatry 2021;15(2):92-95.

Source of support: Nil

Conflict of interest: None

sociodemographic and clinical variables between the two clinical groups.

\section{Materials and Methods}

This study was conducted from January 2015 to December 2015 in Yenepoya Medical College Hospital, Mangaluru which is a tertiary care hospital. Consecutive in-patients aged 18 years and above, presenting with psychotic or nonpsychotic mania as per ICD-10 criteria were included in the study. ${ }^{9}$ Written informed consent was obtained from a close relative, if the patient lacked sufficient insight. Diagnosis was based on clinical interview using MINI (The Mini International Neuropsychiatric Interview English Version 5.0.0). ${ }^{10}$

() The Author(s). 2021 Open Access This article is distributed under the terms of the Creative Commons Attribution 4.0 International License (https://creativecommons. org/licenses/by-nc/4.0/), which permits unrestricted use, distribution, and non-commercial reproduction in any medium, provided you give appropriate credit to the original author(s) and the source, provide a link to the Creative Commons license, and indicate if changes were made. The Creative Commons Public Domain Dedication waiver (http://creativecommons.org/publicdomain/zero/1.0/) applies to the data made available in this article, unless otherwise stated. 
Patients with history of mental retardation, delirium, organic mental disorder or schizophrenia, and other related psychotic disorders were excluded. Ethical clearance was obtained from Institutional Ethics Committee. After the subjects satisfied the inclusion and exclusion criteria, the relevant sociodemographic and clinical data were collected with a specifically designed data sheet. Mini International Neuropsychiatric Interview was used to conduct structured diagnostic interview. This tool has been used in several multicenter clinical trials and epidemiological studies. Young's Mania Rating Scale (YMRS) is one of the most frequently utilized rating scales to assess manic symptoms and was used to rate the severity of mania at intake. ${ }^{11}$

\section{Data Analysis}

The collected data were entered in MS Excel. The categorical variables were presented as percentages/proportions. Continuous variables were expressed in terms of mean and standard deviation. Chi-square test and Fisher exact test were used to study the association between categorical variables and Student $t$-test and Mann-Whitney $U$ test were used to study the association between continuous variables. Data were further analyzed using the software Statistical Package for the Social Sciences (SPSS 22.0 version). ${ }^{12}$

\section{Results}

A total of 60 patients were included in the study using consecutive sampling, 30 patients with nonpsychotic mania and 30 patients with psychotic mania. Our sample consisted of higher number of men $(n=37)$ than women $(n=23)$. About $73.3 \%$ of patients in the psychotic group had low educational status compared to the nonpsychotic group (56.7\%). Most of the participants belonged to the nuclear family (93.3\%). The sample included most of the participants in class 1 of socioeconomic class based on BG Prasad's classification

There was no statistically significant difference with respect to sociodemographic factors like age, gender, educational status, family type, and socioeconomic status between the psychotic and nonpsychotic mania groups (Table 1).

Young's Mania Rating Scale scores were significantly higher in the psychotic mania group than in the nonpsychotic mania group (Mann-Whitney $U=785.5 ; p<0.05$ ). There was also a statistically significant difference in duration of hospital stay between psychotic and nonpsychotic mania groups (Mann-Whitney $U=587.0$; $p=0.04$ ). The difference in number of episodes across categories of recovery was also statistically significant (Mann-Whitney $U=455.0$; $p=0.012$ ). There was no statistically significant difference with respect to clinical factors like number of episodes, age of onset, and substance use between psychotic and nonpsychotic mania groups (Table 2). Patients with psychotic mania had predominantly grandiose delusions (68\%) followed by persecutory delusions (24\%), and referential delusions (8\%). Auditory hallucinations were present in $46.66 \%$ of patients belonging to the psychotic group. They were mostly second person (23.3\%).

During correlation analysis for studying the strength of a linear association between variables, we found a negative correlation between age of onset and number of episodes of psychotic mania group ( $p=-0.477 ; p=0.008$ ). A moderate association between duration of hospitalization and YMRS scores was also observed $(p=0.331 ; p=0.010)$. No linear association was found between age of onset and number of episodes of nonpsychotic mania group $(p=0.057 ; p=0.766)$.

\section{Discussion}

Although men and women are equally likely to get bipolar affective disorder, our sample consisted of more number of men compared with women. There were no statistically significant gender differences between the two groups of psychotic and nonpsychotic mania, similar to the study done by Kessler et al. ${ }^{13}$ In our sample, among men nonpsychotic mania was more prevalent compared to psychotic mania and among women psychotic mania was more prevalent compared to nonpsychotic mania which was similar to the findings of Yildiz and Sachs. ${ }^{14}$

Table 1: Comparison between psychotic and nonpsychotic mania-categorical variables

\begin{tabular}{|c|c|c|c|c|}
\hline Variable & $\begin{array}{c}\text { Nonpsychotic mania } \\
N(\%)\end{array}$ & $\begin{array}{c}\text { Psychotic mania } \\
N(\%)\end{array}$ & $\begin{array}{c}\text { Test (Chi-square/ } \\
\text { Fisher exact) }\end{array}$ & Significance \\
\hline Gender & & & 0.635 & 0.426 \\
\hline Male & $20(33.33)$ & $17(28.33)$ & & \\
\hline Female & $10(16.66)$ & $13(21.66)$ & & \\
\hline Education & & & - & $0.553^{\#}$ \\
\hline Illiterate & $06(10)$ & $10(16.66)$ & & \\
\hline Primary school & $11(18.33)$ & $12(20)$ & & \\
\hline High school & $10(16.66)$ & $06(10)$ & & \\
\hline College & $03(05)$ & $02(3.33)$ & & \\
\hline Family type & & & - & $0.612^{\#}$ \\
\hline Nuclear & $29(48.33)$ & $27(45)$ & & \\
\hline Joint & $01(1.66)$ & $02(3.33)$ & & \\
\hline Other & 0 & $01(1.66)$ & & \\
\hline Socioeconomic status & & & - & $0.727^{\#}$ \\
\hline 1 & $22(36.66)$ & $24(40)$ & & \\
\hline 2 & $05(8.33)$ & $05(8.33)$ & & \\
\hline 3 & $03(05)$ & $01(1.66)$ & & \\
\hline Substance use & & & 1.148 & 0.284 \\
\hline Present & $17(28.33)$ & $21(35)$ & & \\
\hline Absent & $13(21.66)$ & $09(15)$ & & \\
\hline
\end{tabular}

\#Fisher exact 
Psychotic Mania and Nonpsychotic Mania

Table 2: Comparison between psychotic and nonpsychotic mania—continuous variables

\begin{tabular}{lcccc}
\hline Variable & $\begin{array}{c}\text { Nonpsychotic mania } \\
(\text { Mean } \pm \text { SD) }\end{array}$ & $\begin{array}{c}\text { Psychotic mania } \\
(\text { Mean } \pm \text { SD) }\end{array}$ & Mann Whitney U & Significance \\
\hline YMRS score & $23.67 \pm 5.448$ & $33 \pm 6.125$ & 785.5 & $<0.05^{*}$ \\
Age at onset & $30.93 \pm 13.50$ & $29.50 \pm 11.65$ & 433.0 & 0.801 \\
Duration of hospital stay & $9.87 \pm 5.94$ & $13.57 \pm 8.76$ & 587.0 & $0.041^{*}$ \\
No. of episodes & $4.50 \pm 8.39$ & $5.33 \pm 6.89$ & 559.5 & 0.102 \\
\hline
\end{tabular}

*Significant

In our study, the peak age of onset of mania was between the age-group 20-40 years which was similar to a study by Kennedy et al. ${ }^{15}$ In the Bipolar Disorder Course and Outcome Study from India (BiD-ColN study), Grover et al. also reported that the mean age of onset of the first episode of illness in their study sample was 26.3 years. ${ }^{16}$ No significant difference was noted in age of onset in patients with psychotic mania and nonpsychotic mania, which is similar to a study by Carter et al. ${ }^{17}$ It was also noted that there was a negative correlation between age of onset and number of episodes within the psychotic mania group. Early age of onset could lead to more neuropsychological dysfunction, ${ }^{18}$ and as psychosis is neurotoxic, ${ }^{19}$ it could lead to more number of episodes in psychotic mania group. Still, it is not fully clear as to whether early age of onset is a biological vulnerability. ${ }^{20}$ There was no significant difference upon comparison in the number of episodes between the two groups of mania, similar findings were observed in a study from Turkey. ${ }^{21}$

There was a statistically significant difference in YMRS scores of psychotic and nonpsychotic mania and a positive correlation was found between the YMRS score and duration of stay in hospital $(p=0.331 ; p=0.010)$. Those patients who scored high in YMRS at intake had a longer duration of stay in hospital and our findings are in line with other studies. ${ }^{22,23}$ Incomplete recovery was more among patients with psychotic mania compared to patients with nonpsychotic mania. Our study found that the distribution of number of episodes across categories of recovery was different and that patients who had complete inter-episodic recovery were associated with lower number of episodes. Significantly more biological abnormalities, specifically higher kynurenine levels in the cerebrospinal fluid, ${ }^{20}$ high DHEA-S, ${ }^{24}$ and subtle brain changes ${ }^{25}$ in psychotic bipolar patients might be responsible for higher YMRS scores, longer duration of hospital stay, and incomplete recovery. Our findings are similar to a study done in Lebanon. ${ }^{26}$

Generally, patients with mental illness have a heightened risk of medical comorbidities because they often receive suboptimal preventive medical care. ${ }^{27}$ Surprisingly in our study, majority (81.7\%) of the patients did not have any medical comorbidity and only a small number of subjects had comorbidities.

Similar to the earlier studies, ${ }^{28}$ our study participants also had Schneiderian first-rank symptoms. Patients with psychotic mania had predominantly grandiose delusions (68\%) followed by persecutory delusions (24\%), and referential delusions ( $8 \%$ ). Auditory hallucinations were present in $46.66 \%$ of patients belonging to the psychotic group. They were mostly second person (23.3\%). Keck et al. ${ }^{5}$ in their study found $25 \%$ of the patients had hallucinations, and the most common was auditory hallucinations. The psychotic mania group required a longer duration of stay in hospital compared to the nonpsychotic mania group. This can be attributed to the severity of the illness which was more among the psychotic group.
In our study, the sample size was relatively smaller. The sample consisted of hospitalized patients and hence the inference cannot be extrapolated to bipolar patients in the community. This is a crosssectional study which is a study design with its own limitations. Data about compliance and recovery were based on reports from patients, clinicians, and family members who may be subjected to recall bias.

\section{Conclusion}

Psychotic mania tends to be more severe and needs longer duration of stay in hospital compared to nonpsychotic mania. This highlights the need for a distinct yet intense approach to treat psychotic mania in order to reduce the socio-occupational impairment. As the age of onset negatively correlated with number of episodes of psychotic mania, it may be worthwhile to study if early intervention may alter the course of the disorder.

\section{References}

1. Kessler RC, Akiskal HS, Ames M, et al. Considering the costs of bipolar depression. Behav Healthc 2007 Jan;27(1):45-47. PMID: 17310917.

2. Tondo L, Isacsson G, Baldessarini R. Suicidal behaviour in bipolar disorder: risk and Prevention. CNS Drugs 2003;17(7):491-511. DOI: 10.2165/00023210-200317070-00003.

3. World Health Organization. Reducing risks, promoting healthy life. Geneva: The World Health Report; 2002.

4. Goodwin FK, Jamison KR. Manic depressive illness. New York: Oxford University Press; 1990.

5. Keck PE Jr, McElroy SL, Havens JR, et al. Psychosis in bipolar disorder: phenomenology and impact on morbidity and course of illness. Compr Psychiatry 2003;44(4):263-269. DOI: 10.1016/S0010440X(03)00089-0.

6. Azorin JM, Akiskal H, Akiskal K, et al. Is psychosis in DSM-IV mania due to severity? The relevance of selected demographic and comorbid social-phobic features. Acta Psychiatr Scand 2007;115(1):29-34. DOI: 10.1111/j.1600-0447.2006.00841.x.

7. Taylor MA, Abrams R. The phenomenology of mania: a new look at some old patients. Arch Gen Psychiatry 1973;29(4):520-522. DOI: 10.1001/archpsyc.1973.04200040066011.

8. van Rossum I, Haro JM, Tenback D, et al. Stability and treatment outcome of distinct classes of mania. Eur Psychiatry 2008;23(5): 360-367. DOI: 10.1016/j.eurpsy.2008.02.005.

9. World Health Organization. The ICD-10 classification of mental and behavioral disorders. clinical description and diagnostic guidelines. Geneva: WHO; 1992

10. Sheehan DV, Lecrubier $Y$, Sheehan $\mathrm{KH}$, et al. The Mini-International Neuropsychiatric Interview (M.I.N.I.): the development and validation of a structured diagnostic psychiatric interview for DSM-IV and ICD-10. J Clin Psychiatry 1998;59 Suppl 20:22-33;quiz 34-57. PMID: 9881538.

11. Young RC, Biggs JT, Ziegler VE, et al. A rating scale for mania: reliability, validity and sensitivity. Br J Psychiatry 1978;133:429-435. DOI: 10.1192/ bjp.133.5.429.

12. IBM Corp. Released 2013. IBM SPSS Statistics for Windows, Version 22.0. Armonk, NY: IBM Corp. 
13. Kessler RC, Brown RL, Broman CL. Sex differences in psychiatric helpseeking: evidence from four large-scale surveys. J Health Soc Behav 1981 Mar;22(1):49-64. PMID: 7240706.

14. Yildiz A, Sachs GS. Age onset of psychotic versus non-psychotic bipolar illness in men and in women. J Affect Disord 2003;74(2): 197-201. DOI: 10.1016/s0165-0327(02)00003-4.

15. Kennedy N, Boydell J, Kalidindi S, et al. Gender differences in incidence and age at onset of mania and bipolar disorder over a 35-year period in Camberwell, England. Am J Psychiatry 2005;162(2):257-262. DOI: 10.1176/appi.ajp.162.2.257.

16. Grover S, Avasthi A, Chakravarty R, et al. Bipolar disorder course and outcome study from India (BiD-ColN study): sample description and methods. J Affect Disord 2021;280(Pt B):16-23. DOI: 10.1016/j. jad.2020.11.082 [Erratum in: J Affect Disord 2021;281:992. PMID: 33221603].

17. Carter TD, Mundo E, Parikh SV, et al. Early age at onset as a risk factor for poor outcome of bipolar disorder. J Psychiatr Res 2003;37(4): 297-303. DOI: 10.1016/s0022-3956(03)00052-9.

18. Taylor MA, Abrams R. Early- and late-onset bipolar illness. Arch Gen Psychiatry 1981;38(1):58-61. DOI: 10.1001/archpsyc.1981. 01780260060006.

19. McGlashan TH. Is active psychosis neurotoxic? Schizophr Bull 2006;32(4):609-613. DOI: 10.1093/schbul/sbl032.

20. Buoli M, Caldiroli A, Cumerlato Melter C, et al. Biological aspects and candidate biomarkers for psychotic bipolar disorder: a systematic review. Psychiatry Clin Neurosci 2016;70(6):227-244. DOI: 10.1111/ pen.12386.
21. Özyıldırım I, Cakir S, Yazici O. Impact of psychotic features on morbidity and course of illness in patients with bipolar disorder. Eur Psychiatry 2010;25(1):47-51. DOI: 10.1016/j.eurpsy.2009.08.004.

22. Brunelle J, Consoli A, Tanguy ML, et al. Phenomenology, sociodemographic factors and outcome upon discharge of manic and mixed episodes in hospitalized adolescents: a chart review. Eur Child Adolesc Psychiatry 2009;18:185-193. DOI: 10.1007/s00787-008-0715-7.

23. Prabhavathy KS, Kuruvilla PK, Ravindren R, et al. Treatment response in nonpsychotic vs psychotic manias: a follow up study from India. Asian J Psychiatr 2017;26:104-108. DOI: 10.1016/j.ajp.2017.01.006. PMID: 28483069

24. Buoli M, Caldiroli A, Serati M, et al. Sex steroids and major psychoses: which role for DHEA-S and progesterone. Neuropsychobiology 2016;73(3):178-183. DOI: 10.1159/000444922.

25. Ong D, Walterfang M, Malhi GS, et al. Size and shape of the caudate nucleus in individuals with bipolar affective disorder. Aust $\mathrm{N} \mathrm{Z} \mathrm{J}$ Psychiatry 2012;46(4):340-351. DOI: 10.1177/0004867412440191.

26. Nehme E, Obeid S, Hallit $S$, et al. Impact of psychosis in bipolar disorder during manic episodes Int J Neurosci 2018;128(12):1128-1134. DOI: 10.1080/00207454.2018.1486833.

27. Carney CP, Jones L, Woolson RF. Medical comorbidity in women and men with schizophrenia: a population-based controlled study. J Gen Intern Med 2006;21(11):1133-1137. DOI: 10.1111/j.15251497.2006.00563.x.

28. Carlson GA, Goodwin FK. The stages of mania. A longitudinal analysis of the manic episode. Arch Gen Psychiatry 1973;28(2):221-228. DOI: 10.1001/archpsyc.1973.01750320053009. 